\title{
Long-term sperm cryopreservation does not affect post-thaw survival rates
}

\author{
Juliana R. Pariz ${ }^{1,2,3,4}$, Rosa Alice C. Monteiro ${ }^{1}$, Jorge Hallak ${ }^{1,2,3,4}$
}

\begin{abstract}
${ }^{1}$ Androscience, Science and Innovation Center in Andrology and High-Complex Clinical and Andrology Laboratory. São Paulo, Brazil

${ }^{2}$ Institute for Advanced Studies, University of São Paulo (IEA-USP), São Paulo, Brazil

${ }^{3}$ Section of Andrology - Division of Urology, Faculdade de Medicina da Universidade de São Paulo, São Paulo, Brazil

${ }^{4}$ Reproductive Toxicology Unit - Department of Pathology, Faculdade de Medicina da Universidade de São Paulo, São Paulo, Brazil
\end{abstract}

This study was presented at the GAP 2016 Challenging Cancer Congress, São Paulo, 2016.

\begin{abstract}
Objective: To compare cryosurvival rates of human spermatozoa in a prolonged period of cryopreservation.

Methods: This retrospective study involved 33 cryopreserved semen samples from patients with cancer, between 2002 and 2011. The semen sample was obtained by masturbation and initial semen analysis was performed. The cryoprotectant solution was added and samples were frozen in liquid nitrogen in a slow step-wise process. For thawing, the samples were incubated at $25.0^{\circ} \mathrm{C}$ for $15 \mathrm{~min}$, followed by incubation at $36.7^{\circ} \mathrm{C}$ for $15 \mathrm{~min}$. The cryosurvival rate (CS) was calculate by $\mathrm{CS}=[(\%$ total motile sperm post-thaw $) \times 100 /$ (\% total motile sperm/tube)]. Each study sample was divided into three aliquots (Study Group; $n=23$ ): (I) official patient sample, which was kept cryopreserved for subsequent Assisted Reproduction procedure, cryopreserved between 2002 and 2011; (II) sample destined to post-thaw tests, performed after the sample had been kept cryopreserved for 24 hours; and (III) study sample. Only in 2014, after 3-12 years of cryopreservation, the study samples were thawed and evaluated. To validate the study design, a Validation Group was created including 10 samples obtained between 2014 and 2016, using the same methodology in the study samples. The data was analyzed using the T-test, with a significant $p$-value of $5 \%$.

Results: The mean age was $29.93 \pm 9.57$ years in the Study Group and $21.80 \pm 6.49$ years in the Validation Group. No significant difference between the Validation and Study Groups was found in the initial semen analysis $(p>0.05)$. After 24 hours of cryopreservation, the cryosurvival rate was $26.11 \pm 46.36 \%$ in the Study Group and $23.71 \pm 57.06 \%$ in the Validation Group. Aliquots of the same sample preserved from $3-12$ years demonstrated $23.71 \pm 57.06 \%$ of cryosurvival rate. Thus, no significant difference was found vis-à-vis the cryosurvival rates $(p=0.56)$.

Conclusion: We concluded that the method introduced in the late 1990s, which enables the removal of debris, potentially toxic elements and generators of reactive oxygen species from the seminal sample before cryopreservation, exhibited efficiency in maintaining the same cryosurvival rate after an extended period.
\end{abstract}

Keywords: cryopreservation, cryosurvival rates, sperm, sperm bank

\section{INTRODUCTION}

Sperm cryopreservation is the main method for preserving male fertility, which was applied in such situations as artificial insemination with donor sperm, in vitro fertilization (IVF) program with sperm obtained by microsurgery, high-risk professions and patients undergoing chemotherapy, radiotherapy and other immunosuppressive therapies (Hallak et al., 2000a; Li et al., 2010). This process may have several negative effects in sperm, which vary according to the characteristics and/or sample handling.

Damage caused by wide temperature variation, ranging from $36.6^{\circ} \mathrm{C}$ to $-196.0^{\circ} \mathrm{C}$, such as thermal shock, formation of ice crystals, dehydration and increased intracellular salt concentration caused by osmotic shock (Stanic et al., 2000) can impair the structural and functional integrity of spermatozoa via reduced motility and vitality due to mitochondrial damages and in plasma and acrosome membranes (Succu et al., 2011), increased DNA fragmentation and generation of reactive oxygen species, lipid peroxidation and apoptosis (Zribi et al., 2010; Wang et al., 1997; Alvarez \& Storey, 1992; Paasch et al., 2004). These adverse effects were found in 25 to $75 \%$ of spermatozoa undergoing the cryopreservation process (Chian \& Quinn, 2010; Hallak et al., 1999a).

Thus, the improvement of techniques employed in cryopreservation processes, particularly in sample handling and application of diluents and cryoprotectants, which contain osmotically active ingredients, such as glycerol, which is capable of reducing intracellular water and thus reduce the damage caused by the formation of ice crystals. Other components used include glucose, sodium chloride, and human serum albumin, which protect sperm against aggression during laboratory handling, reduce osmotic and oxidative stress, reduce the freezing-point of water and aid in buffering the sample (Chian \& Quinn, 2010; Creemers et al., 2011). Another important factor for effective cryopreservation is determining the duration of cooling, steam and storage in liquid nitrogen. Similarly, the standardization of thawing steps may enable a satisfactory survival rate of cells, particularly if it is performed following the same steps of freezing process but in reverse (Hallak et al., 1999a; 2000b).

A large number of studies involve sperm cryopreservation using various techniques and species; however, the low recovery rate of viable sperm is still considered unsatisfactory for artificial insemination, required for classic IVF and intracytoplasmic sperm injection (ICSI) procedures (Chan et al., 1993; Hallak et al., 1998a; 1998b; 1999b; 2000a; 2000b; Vutyavanich et al., 2010). In all methods of cryopreservation, the biological activity of sperm can be stored indefinitely in liquid nitrogen, despite the potential 
morphological reactions occurring at a temperature of $-196.0^{\circ} \mathrm{C}$. The usual question is how to choose the most appropriate procedure with minimal biological damage, ensuring offspring safety and maintaining the effectiveness of the protocol developed in the laboratory. Each sample is different, even samples obtained from the same patient. Faced with this issue, there is a need for an evaluation to validate the cryopreservation protocol.

Usually, an analysis of sperm survival from a small frozen aliquot is performed 24 hours after freezing to confirm the survival rate of the sample (Hallak et al., 1998a), with the goal of providing a preview of how the sample will behave when thawed. Information on sperm viability after years of thawing is scarce in the literature; however, it has been suggested that the default period is 10 years to store sperm, and it has been shown to take up to 55 years in cases of cancer survivors (Sharma, 2011).

In an attempt to analyze the effects of time on the quality of cryopreserved samples, the objective of this study was to compare cryosurvival rates of human spermatozoa in a prolonged period of cryopreservation. In addition, we describe a modified cryopreservation technique adopted in our laboratory, using a slow method, with nitrogen vapor, adding an intermediate step of selecting spermatozoa with better motility and removing elements that are potentially toxic and generators of reactive oxygen species (ROS).

\section{MATERIALS AND METHODS}

In this retrospective study, carried out between 2002 and 2016, thirty-three cryopreserved semen samples (23 study samples and 10 validation samples) were included from reproductive-age patients who chose to donate their samples for scientific research and signed the consent form. This Ethics Committee of the University of São Paulo approved this study (031/2013).

We recruited the patients from private Andrology clinics, with diagnoses of penis and testicle tumors, leukemia, osteosarcoma, adenocarcinoma, and others; and donated samples that were cryopreserved before the start of treatment with chemotherapy and radiotherapy. As for inclusion criteria, we selected patients with diagnosis of cancer that performed initial seminal analysis before the sperm cryopreservation. Exclusion criteria included seminal irregularities in semen evaluation that impaired the post-thawed analysis, such as necrozoospermia, azoospermia and severe oligozoospermia.

Semen sample was obtained by masturbation and prior semen analysis was performed following the current criteria of the World Health Organization (WHO, 1999; 2010). After liquefaction, macroscopic and microscopic parameters were analyzed.

Procedures were carried out to optimize the sample before cryopreservation, such as (i) semen washing, in which debris and cell generators of ROS was removed; (ii) seminal processing by the Isolate ${ }^{\circledR}$ method (Irvine Scientific, Santa Ana, USA), to retrieve viable spermatozoa; or (iii) simple centrifugation to concentrate the spermatozoa in a smaller volume. The semen washing provides the highest yield of spermatozoa and is adequate if semen samples are of good quality; however, with excess cellular debris and round cells. We diluted the seminal sample with modified Human Tubal Fluid ${ }^{\circledR}$ (modified-HTF; Irvine Scientific, Santa Ana, USA) 1:2 to promote removal of seminal plasma and centrifuged at $400 \mathrm{~g}$ for $15 \mathrm{~min}$. The supernatants were carefully aspirated, and the sperm pellet was resuspended in modified-HTF. The seminal processing by the Isolate method provides the best selection of good-quality spermatozoa, giving good separation from the cell types, because it reduces non-progressive and immotile sperm concentration. We created a $1 \mathrm{ml}$ density-gradient medium barrier of $40 \%(\mathrm{v} / \mathrm{v})$ density-gradient medium over $1 \mathrm{ml}$ of $80 \%(\mathrm{v} / \mathrm{v})$ density-gradient medium, and $1 \mathrm{ml}$ of seminal sample was added above the density-gradient media. The sample was centrifuged at $400 \mathrm{~g}$ for $15 \mathrm{~min}$, the supernatants were carefully aspirated and the sperm pellet was resuspended in $1 \mathrm{ml}$ of modified-HTF. A simple washing was performed, and the sperm pellet was resuspended in $1 \mathrm{ml}$ of modified-HTF. In samples with low sperm concentration, we performed a simple centrifugation (400 $\mathrm{g}$ for $15 \mathrm{~min}$ ) and removed part of the supernatant, so that the sample became more concentrated in a smaller volume $(1 \mathrm{ml})$.

For sperm cryopreservation, we added the cryoprotectant solution in the $1: 1$ ratio, at $36.7^{\circ} \mathrm{C}$ (Test Yolk Buffer ${ }^{\circledR}$; Scientific Irvine, Santa Ana, USA). Next, the samples were frozen in a slow step-wise process, starting with the equilibration period ( 8 minutes) at $4{ }^{\circ} \mathrm{C}$, followed by a phase transition ( 2 hours) in liquid nitrogen vapor at $-79^{\circ} \mathrm{C}$ and ending with a dip in liquid nitrogen at $-196^{\circ} \mathrm{C}$ (Sherman, 1986). For thawing, the samples were incubated at $25.0^{\circ} \mathrm{C}$ for $15 \mathrm{~min}$, followed by incubation at $36.7^{\circ} \mathrm{C}$ for $15 \mathrm{~min}$. The cryosurvival rate (CS) was calculate by $\mathrm{CS}=$ [(\% total motile sperm post-thaw $) \times 100 /(\%$ total motile sperm/tube)] (Henry et al., 1993).

Each sample from the Study Group $(n=23)$ was divided into three aliquots: (I) official patient sample, which was kept cryopreserved for subsequent Assisted Reproduction procedures, cryopreserved between 2002 and 2011; (II) sample destined to post-thaw tests, performed after the sample had been kept cryopreserved for 24 hours; and (III) study sample. In 2014, the study samples were thawed and evaluated. To validate the study design we created a Validation Group, consisting of 10 samples obtained in 2014-2016, which were cryopreserved and thawed after 24 hours, using the same methodology of the study samples.

The statistical analysis was performed using the SPSS Statistics 19 software. We analyzed the results using the paired T-test (cryosurvival in the Study Group), and independent T-test (Study versus Validation groups) and adopted a significant $p$-value of $5 \%$.

\section{RESULTS}

Table 1 displays the clinical characteristics of the subjects included in study. Their mean age was 29.93 [Standard Deviation (SD) \pm 9.57 years old] in the Study Group and 21.80 (SD \pm 6.49 ) in the Validation Group. All the subjects were submitted to semen cryopreservation before cancer treatment (chemotherapy and/or radiotherapy).

The initial characteristics of semen samples are depicted in Table 2. No significant difference between the Validation and Study Groups was found concerning sperm concentration $(p=0.259)$, progressive total number $(p=0.120)$, total motility $(p=0.589)$, progressive motility $(p=0.828)$, non-progressive motility $(p=0.264)$ and non-mobile sperm $(p=0.840)$.

After 24 hours of cryopreservation, the cryosurvival rate was $26.11 \pm 46.36 \%$ in the Study Group and $23.71 \pm 57.06 \%$ in the Validation Group. Aliquots of the same sample preserved for 3 and 12 years demonstrated $23.71 \pm 57.06 \%$ of cryosurvival rate (Table 3 ).

The Validation Group had $29 \%$ cryosurvival rate in recently cryopreserved samples. Thus, no significant difference was found in sperm cryosurvival rates $(p=0.56)$.

\section{DISCUSSION}

Sperm cryopreservation process is an important method for gametes preservation, one that maintains cell function and genetic information, enabling future paternity for men with progressive loss of fertility, immunosuppressive treatment or infertility risk (Sharma, 2011). Storage in 
Table 1. Clinical characteristics of the subjects included in the study

\begin{tabular}{|c|c|c|c|c|}
\hline Period stored & Samples (n) & Frequency $(\%)$ & Clinic diagnosis & Years-old \\
\hline \multicolumn{5}{|l|}{ 1. Study Group } \\
\hline 12 years & 1 & 4.35 & Testis tumor & 30 \\
\hline \multirow{4}{*}{10 years } & 1 & 4.35 & $\begin{array}{l}\text { Pre-Chemotherapy } \\
\text { (non-informed tumor) }\end{array}$ & 39 \\
\hline & 1 & 4.35 & Testis tumor & 37 \\
\hline & 1 & 4.35 & $\begin{array}{l}\text { Pre-Chemotherapy } \\
\text { (non-informed tumor) }\end{array}$ & 17 \\
\hline & 1 & 4.35 & $\begin{array}{l}\text { Pre-Chemotherapy } \\
\text { (non-informed tumor) }\end{array}$ & 39 \\
\hline \multirow{4}{*}{9 years } & 1 & 4.35 & Penis tumor & 32 \\
\hline & 1 & 4.35 & Leukemia & 21 \\
\hline & 1 & 4.35 & Osteosarcoma & 16 \\
\hline & 1 & 4.35 & Testis nodule & 36 \\
\hline 8 years & 1 & 4.35 & Sigmoid adenocarcinoma & 40 \\
\hline 6 years & 1 & 4.35 & $\begin{array}{l}\text { Pre-Chemotherapy } \\
\text { (non-informed tumor) }\end{array}$ & 39 \\
\hline 5 years & 1 & 4.35 & $\begin{array}{l}\text { Pre-Chemotherapy } \\
\text { (non-informed tumor) }\end{array}$ & 39 \\
\hline \multirow{3}{*}{3 years } & 4 & 17.38 & Mediastinal Seminoma & 22 \\
\hline & 6 & 26.08 & $\begin{array}{l}\text { Pre-Chemotherapy } \\
\text { (non-informed tumor) }\end{array}$ & 14 \\
\hline & 1 & 4.35 & Testis tumor & 28 \\
\hline Total & 23 & 100 & & Mean $=29.93 \pm 9.57$ y.o. \\
\hline \multicolumn{5}{|l|}{ 2. Validation Group } \\
\hline \multirow{10}{*}{24 hours } & 1 & 10 & Leukemia & 28 \\
\hline & \multirow{2}{*}{2} & \multirow{2}{*}{20} & \multirow{2}{*}{ Testis tumor } & 23 \\
\hline & & & & 22 \\
\hline & 1 & 10 & Sarcoma & 16 \\
\hline & 1 & 10 & Lymphoma & 19 \\
\hline & 1 & 10 & Nasopharynges cancer & 15 \\
\hline & 1 & 10 & Rhabdomyosarcoma & 20 \\
\hline & 1 & 10 & Adenocarcinoma & 37 \\
\hline & 1 & 10 & Hypophysis macroadenoma & 20 \\
\hline & 1 & 10 & Mediastinal tumor & 18 \\
\hline Total & 10 & 100 & & Mean $=21.80 \pm 6.49 y .0$ \\
\hline
\end{tabular}

liquid nitrogen and addition of cryoprotectant substances are standard worldwide procedures for sample maintenance for indefinite amounts of time. The technique's disadvantage is a significant reduction in sperm quality throughout the cryopreservation process, mainly sperm motility, and only 30 to $40 \%$ of the sperm remain viable after thawing (Hallak et al., 2000a; 2000b; Ranganathan et al., 2002); being even less when not cryopreserved properly. Our study was carried out in a specialized andrology laboratory, and the results corroborate literature reports, since our cryosurvival rates in cancer subjects was 30\%, regardless of storage period in liquid nitrogen. Calculations for determining the survival rates are based on post-thaw sperm motility, because it is an independent predictor of its functional, metabolic and DNA integrity. Sperm that are motile after thawing are the ones that have survived the stress of freezing and thawing and have proven themselves functionally intact to fertilize oocytes and give rise to a viable embryo (Agarwal et al., 1995). Thus, one must consider that even non-motile sperm can be viable, which requires sperm vitality tests.

Establishing effective protocols for human sperm cryopreservation with minimum damage to cells or to improve the sperm quality post-thawing has been discussed and can contribute to Assisted Reproduction techniques. Supplementation of culture medium for freezing 
Table 2. Initial semen characteristics of subjects included in study

\begin{tabular}{|c|c|c|c|}
\hline & Study group & Validation group & p value* \\
\hline \multicolumn{4}{|c|}{ Sperm concentration (million/mL) } \\
\hline Mean \pm SD & $39.58 \pm 26.24$ & $60.86 \pm 78.80$ & 0.259 \\
\hline Min-Max & $0.3-100.0$ & $11.3-298.0$ & \\
\hline \multicolumn{4}{|c|}{ Progressive total number (million) } \\
\hline Mean $\pm S D$ & $35.69 \pm 29.83$ & $84.22 \pm 132.99$ & 0.120 \\
\hline Min-Max & $0.1-106.0$ & $1.6-596.0$ & \\
\hline \multicolumn{4}{|c|}{ Total motility (\%) } \\
\hline Mean \pm SD & $60.90 \pm 11.75$ & $63.70 \pm 19.71$ & 0.589 \\
\hline Min-Max & $30.0-74.0$ & $30.0-95.0$ & \\
\hline \multicolumn{4}{|c|}{ Progressive motility (\%) } \\
\hline Mean \pm SD & $42.74 \pm 15.26$ & $42.10 \pm 25.12$ & 0.828 \\
\hline Min-Max & $15.0-67.0$ & $0.0-90.0$ & \\
\hline \multicolumn{4}{|c|}{ Non-progressive motility (\%) } \\
\hline Mean \pm SD & $18.40 \pm 9.52$ & $21.60 \pm 8.28$ & 0.264 \\
\hline Min-Max & $1.0-36.0$ & $5.0-40.0$ & \\
\hline \multicolumn{4}{|c|}{ Non-mobile (\%) } \\
\hline Mean \pm SD & $35.20 \pm 14.05$ & $36.30 \pm 19.71$ & 0.840 \\
\hline Min-Max & $0.0-70.0$ & $5.0-70.0$ & \\
\hline
\end{tabular}

SD: Standard deviation

Min-Max: Minimum and maximum value

* Independent T-test

\begin{tabular}{|c|c|c|c|}
\hline & $\begin{array}{c}\text { Post-thaw test after } 24 \\
\text { hours }\end{array}$ & $\begin{array}{c}\text { Post-thaw test after } 3-12 \\
\text { years }\end{array}$ & p-value* \\
\hline \multicolumn{4}{|c|}{ Cryo-survival rate (\%) } \\
\hline Mean $\pm S D$ & $26.11 \pm 46.36$ & $23.71 \pm 57.06$ & 0.892 \\
\hline Min-Max & $0.0-68.0$ & $0.0-57.00$ & \\
\hline
\end{tabular}

SD: Standard deviation

Min-Max: Minimum and maximum value

* Paired T-test

with proteins, antioxidants and stimulants to avoid damage to spermatozoa has been widely studied, but the toxicity of these substances, both for the sperm or for the oocyte, remains unclear. The addition of caffeine $2 \mathrm{mM}$ (1,3,7-trimethylxanthine; Sigma-Aldrich, USA) in postthaw samples described by Pariz \& Hallak (2016) was associated with increased mitochondrial activity and $38 \%$ increase in progressive motility, suggesting that caffeine may be an important tool applied to seminal samples post-thawing. Moreover, the caffeine $(2 \mathrm{mM})$ - melatonin $(2 \mathrm{mM})$ association seems to preserve mitochondrial activity (Pariz et al., 2019). We can also cite the addition of glutamine and pentoxifylline to semen samples, improving motility and fertilization potential (Renard et al., 1996; Esteves et al., 2007), catalase and ascorbate, which increase motility percentages and reduce ROS production ( $\mathrm{Li}$ et al., 2010).

Despite the fact that cryopreserved samples remain in liquid nitrogen for decades and are viable for fertilization (van Casteren et al., 2008), few studies have been devoted to analyze the effects of time storage on sperm quality
(Huang et al., 2004; Rofeim \& Gilbert, 2005). Studies that used frozen-thawed testicular tissue (2-4 years of cryostorage) showed that ICSI, pregnancy and neonatal outcomes are not affected by the cryopreservation duration (Huang et al., 2004; Tsai et al., 2013). In another study, the authors showed that almost $40 \%$ of the patients were able to achieve a healthy live birth with post-thaw semen, and the type of cancer pre-cryopreservation or ART (Agarwal et al., 2004) did not affect their chances for success. However, no study has reported cryosurvival or fertilization rates from cryopreserved samples for 10 years or more.

Knowledge of pre-cryopreservation and post-thaw sperm quality plays a role in public health policies and can be used to educate patients who initiate cancer treatment and wish future paternity. Side effects of cancer treatment, such as gonad toxicity and testicular dysfunction, have great potential for affecting fertility, about $25 \%$ chance of recovering failure (Moss et al., 2016; Williams, 2013). Thus, oncologists, surgeons, and physicians involved in cancer therapy should discuss options available to store spermatozoa before treatment, because each 
cryopreserved sample is an opportunity to reach a future gestation. The chances of pregnancy depends on the individual quality of each sample, as well as their initial functional characteristics.

Therefore, post -thaw tests are important to predict pregnancy probabilities during the cryopreservation period and to determine the amount of collection/samples to be stored. In the present study, sperm motility was evaluated (\% cryosurvival) 24 hours after freezing and compared with samples thawed 3-12 years before. Regardless of storage period in liquid nitrogen, these samples have similar cryosurvival rates. In addition, samples cryopreserved and thawed in 2014-2016 confirmed that the cryosurvival rate was not affected by the storage period. Finally, we were able to validate the consistency and reproducibility of the cryopreservation protocol adopted in our laboratory, because no changes were found in the rates of cryosurvival over the years 2002 and 2016. Thus, it is possible to advise for fertility preservation in liquid nitrogen to patients desiring future pregnancies, who were mainly young males with family plans for more than 12 years.

It is important to report that the number of samples included in this study was a limitation, since authorization for storing samples for study purposes was required. In addition, only samples from cancer subjects were included, and this may be a determining factor for cryosurvival rate having been around $25 \%$. Other metabolic and reproductive diseases or sperm functional characteristics may influence the rate of sperm recovery.

\section{CONCLUSION}

We conclude that the method introduced in the late 1990 s showed no difference in rates of cryosurvival over the years. The protocol used in our laboratory, which includes removal of debris, potentially toxic elements and generators of ROS from the seminal sample before cryopreservation was efficient in maintaining the rate of cryosurvival after an extended period. In addition, this technique also presented high reproducibility because the technique applied to Assisted Reproduction was performed according to sperm quality after thawing, which enabled the protocol to be adopted by our laboratory for validation.

\section{Financial support}

Androscience, Science and Innovation Center in Andrology and High-Complex Clinical and Andrology Laboratory, São Paulo, Brazil. Capes-PROEX National Council for Scientific and Technological Development (CNPq, Research Productivity Scholarship 2, n³01373/2013).

\section{CONFLICT OF INTEREST}

All authors declare no financial conflict of interests.

\section{Corresponding author:}

Juliana R. Pariz

Androscience

Science and Innovation Center in Andrology

High-Complex Clinical and Andrology Laboratory

São Paulo, SP, Brazil.

E-mail: juliana_rp@hotmail.com,

lab@androscience.com.br

\section{REFERENCES}

Agarwal A, Tolentino MV Jr, Sidhu RS, Ayzman I, Lee JC, Thomas AJ Jr, Shekarriz M. Effect of cryopreservation on semen quality in patients with testicular cancer. Urology. 1995;46:382-9. PMID: 7660514 DOI: 10.1016/S00904295(99)80224-6
Agarwal A, Ranganathan P, Kattal N, Pasqualotto F, Hallak J, Khayal S, Mascha E. Fertility after cancer: a prospective review of assisted reproductive outcome with banked semen specimens. Fertil Steril. 2004;81:342-8. PMID: 14967371 DOI: $10.1016 /$ j.fertnstert.2003.07.021

Alvarez JG, Storey BT. Evidence for increased lipid peroxidative damage and loss of superoxide dismutase activity as a mode of sublethal cryodamage to human sperm during cryopreservation. J Androl. 1992;13:232-41. PMID: 1601742

Chan SY, Pearlstone A, Uhler M, Tucker M, Greenspoon R, Leung $A$, Wang $C$. Human spermatozoal tail hypo-osmotic swelling test, motility characteristics in hypotonic saline, and survival of spermatozoa after cryopreservation. Hum Reprod. 1993;8:717-21. PMID: 8314966 DOI: 10.1093/ oxfordjournals.humrep.a138127

Chian RC, Quinn P. Fertility Cryopreservation. New York: Cambridge University Press; 2010.

Creemers E, Nijs M, Vanheusden E, Ombelet W. Cryopreservation of human sperm: efficacy and use of a new nitrogen-free controlled rate freezer versus liquid nitrogen vapour freezing. Andrologia. 2011;43:392-7. PMID: 21848872 DOI: $10.1111 /$ j.1439-0272.2010.01070.x

Esteves SC, Spaine DM, Cedenho AP. Effects of pentoxifylline treatment before freezing on motility, viability and acrosome status of poor quality human spermatozoa cryopreserved by the liquid nitrogen vapor method. Braz J Med Biol Res. 2007;40:985-92. PMID: 17653453 DOI: $10.1590 /$ S0100-879X2006005000118

Hallak J, Sharma RK, Thomas AJ Jr, Agarwal A. Why cancer patients request disposal of cryopreserved semen specimens posttherapy: a retrospective study. Fertil Steril. 1998a;69:889-93. PMID: 9591498 DOI: 10.1016/S00150282(98)00035-1

Hallak J, Hendin BN, Thomas AJ Jr, Agarwal A. Investigation of fertilizing capacity of cryopreserved spermatozoa from patients with cancer. J Urol. 1998b;159:1217-20. PMID: 9507838 DOI: 10.1016/S0022-5347(01)63561-4

Hallak J, Kolettis PN, Sekhon VS, Thomas AJ, Agarwal A. Sperm cryopreservation in patients with testicular cancer. Urology. 1999a; 54:894-9. PMID: 10565754 DOI: 10.1016/ S0090-4295(99)00267-8

Hallak J, Kolettis PN, Sekhon VS, Thomas AJ Jr, Agarwal A. Cryopreservation of sperm from patients with leukemia: is it worth the effort? Cancer. 1999b;85:1973-8. PMID: 10223238 DOI: 10.1002/(SICI)1097-0142(19990501)85: 9\%3C1973: :AID-CNCR14\%3E3.0.CO;2-0

Hallak J, Mahran AM, Agarwal A. Characteristics of cryopreserved semen from men with lymphoma. J Assist Reprod Genet. 2000a;17:591-4. PMID: 11209541 DOI: 10.1023/a:1026443510493

Hallak J, Mahran A, Chae J, Agarwal A. The effects of cryopreservation on semen from men with sarcoma or carcinoma. J Assist Reprod Genet. 2000b;17:218-21. PMID: 10955246 DOI: $10.1023 / A: 1009443901307$ 
Henry MA, Noiles EE, Gao D, Mazur P, Critser JK. Cryopreservation of human spermatozoa IV. The effects of cooling rate, and warming rate on the maintenance of motility, plasma membrane integrity, and mitochondrial function. Fertil Steril. 1993;60:911-8. PMID: 8224279 DOI: $10.1016 /$ S0015-0282(16)56296-7

Huang FJ, Lan KC, Lin YC, Tsai MY, Kung FT, Chang SY. Impact of duration of cryopreservation of spermatozoa obtained through testicular sperm extraction on intracytoplasmic sperm injection. Fertil Steril. 2004;81:1405-7. PMID: 15136113 DOI: 10.1016/j.fertnstert.2003.12.017

Li Z, Lin Q, Liu R, Xiao W, Liu W. Protective effects of ascorbate and catalase on human spermatozoa during cryopreservation. J Androl. 2010;31:437-44. PMID: 19834132 DOI: $10.2164 /$ jandrol.109.007849

Moss JL, Choi AW, Fitzgerald Keeter MK, Brannigan RE. Male adolescent fertility preservation. Fertil Steril. 2016;105:267-73. PMID: 26707904 DOI: 10.1016/j.fertnstert.2015.12.002

Paasch U, Sharma RK, Gupta AK, Grunewald S, Mascha EJ, Thomas AJ Jr, Glander HJ, Agarwal A. Cryopreservation and thawing is associated with varying extent of activation of apoptotic machinery in subsets of ejaculated human spermatozoa. Biol Reprod. 2004;71:1828-37. PMID: 15286043 DOI: $10.1095 /$ biolreprod.103.025627

Pariz JR, Hallak J. Effects of caffeine supplementation in post-thaw human semen over different incubation periods. Andrologia. 2016;48:961-6. PMID: 26781217 DOI: 10.1111/and. 12538

Pariz JR, Ranéa C, Monteiro RAC, Evenson DP, Drevet JR, Hallak J. Melatonin and Caffeine Supplementation Used, Respectively, as Protective and Stimulating Agents in the Cryopreservation of Human Sperm Improves Survival, Viability, and Motility after Thawing compared to Traditional TEST-Yolk Buffer. Oxid Med Cell Longev; 2019. in press DOI: $10.1155 / 2019 / 6472945$

Ranganathan P, Mahran AM, Hallak J, Agarwal A. Sperm cryopreservation for men with nonmalignant, systemic diseases: a descriptive study. J Androl. 2002;23:71-5. PMID: 11780925 DOI: 10.1002/jand.2002.23.1.71

Renard P, Grizard G, Griveau JF, Sion B, Boucher D, Le Lannou D. Improvement of mo tility and fertilization potential of postthaw human sperm using glutamine. Cryobiology. 1996;33:311-9. PMID: 8689888 DOI: 10.1006/ cryo.1996.0031

Rofeim O, Gilbert BR. Long-term effects of cryopreservation on human spermatozoa. Fertil Steril. 2005;84:536-7. PMID: 16084905 DOI: 10.1016/j.fertnstert.2005.02.035

Sharma V. Sperm storage for cancer patients in the UK: a review of current practice. Hum Reprod. 2011;26:293543. PMID: 21873609 DOI: 10.1093/humrep/der281
Sherman JK. Current status of clinical cryobanking of human semen. In: Paulson JD, Negro-Vilar A, Lucena E, Martinia L, eds. Andrology: Male Fertility and Sterility. New York: Academic Press; 1986. p. 517-49.

Stanic P, Tandara M, Sonicki Z, Simunic V, Radakovic B, Suchanek E. Comparison of protective media and freezing techniques for cryopreservation of human semen. Eur J Obstet Gynecol Reprod Biol. 2000;91:65-70. PMID: 10817881 DOI: $10.1016 /$ S0301-2115(99)00255-9

Succu S, Berlinguer F, Pasciu V, Satta V, Leoni GG, Naitana $\mathrm{S}$. Melatonin protects ram spermatozoa from cryopreservation injuries in a dose-dependent manner. J Pineal Res. 2011;50:310-8. PMID: 21214627 DOI: 10.1111/j.1600079X.2010.00843.x

Tsai YR, Lan KC, Tsai CC, Lin PY, Kung FT, Liu YC, Huang FJ. Pregnancy outcome and neonatal data of children born after intracytoplasmic sperm injection with a different duration of cryopreservation of spermatozoa obtained through testicular sperm extraction. Taiwan J Obstet Gynecol. 2013;52:329-34. PMID: 24075368 DOI: 10.1016/j. tjog.2012.08.003

van Casteren NJ, van Santbrink EJ, van Inzen W, Romijn JC, Dohle GR. Use rate and assisted reproduction technologies outcome of cryopreserved semen from 629 cancer patients. Fertil Steril. 2008;90:2245-50. PMID: 18191846 DOI: $10.1016 /$ j.fertnstert.2007.10.055

Vutyavanich T, Piromlertamorn W, Nunta S. Rapid freezing versus slow programmable freezing of human spermatozoa. Fertil Steril. 2010;93:1921-8. PMID: 19243759 DOI: 10.1016/j.fertnstert.2008.04.076

Wang AW, Zhang $H$, Ikemoto I, Anderson DJ, Loughlin KR. Reactive oxygen species generation by seminal cells during cryopreservation. Urology. 1997;49:921-5. PMID: 9187701 DOI: $10.1016 /$ S0090-4295(97)00070-8

Williams $\mathrm{DH}$ 4th. Fertility preservation in the male with cancer. Curr Urol Rep. 2013;14:315-26. PMID: 23812951 DOI: $10.1007 / \mathrm{s} 11934-013-0345-6$

World Health Organization (WHO). Laboratory manual for the examination of human semen and sperm-cervical mucus interaction. 4th ed. New York: Cambridge University Press; 1999.

World Health Organization (WHO). Laboratory manual for the examination and processing of human semen. 5th ed. Geneva: WHO; 2010.

Zribi N, Feki Chakroun N, El Euch H, Gargouri J, Bahloul A, Ammar Keskes L. Effects of cryopreservation on human sperm deoxyribonucleic acid integrity. Fertil Steril. 2010;93:159-66. PMID: 19027111 DOI: $10.1016 / j . f e r t n-$ stert.2008.09.038 